\title{
Research on the Inheritance and Development of Qiang Embroidery Art under the Background of Cultural and Creative Industries
}

\author{
Weiping Yuan ${ }^{1}$, Lihua $\mathrm{Wu}^{1}$ \\ ${ }^{1}$ Polytechnic institute of Jiangxi Science and Technology Normal University, Jiangxi, Nanchang, 330000
}

Keywords: Cultural and creative industries; embroidery art; inheritance and development

\begin{abstract}
Chinese culture has a long history. Countless local cultural and artistic works have become the treasures of world art. Among them, Chinese embroidery art is a unique artistic expression in the world. In recent years, the unique craftsmanship of the embroidery, which is not only the four famous embroidery, has gradually attracted the attention of the people. Under the background of the current implementation of cultural and creative industries in China, Qiang embroidery should be effectively passed down, to further deepen the development of embroidery, with the embroidery as the local characteristics of Jiangxi, forming a creative industry chain. This paper will conduct in-depth research on the inheritance and development of the embroidery art in the context of cultural and creative industries, aiming to give some practical suggestions to the local creative industries in Jiangxi.
\end{abstract}

\section{Introduction}

In order to promote China's local economy, the state advocates independent research and development of cultural and creative industries between regions, strives to explore special cultural characteristics, and utilizes the unique culture between regions to develop local cultural and characteristic industries integrating tourism consumption. This cultural and creative industry can meet the economic needs of the region. Therefore, the embroidery has become a unique feature of the development of local industries in Jiangxi. The embroidery is different from the four famous embroidery. From the material selection to the whole process, it is full of the characteristics of the culture. The selection of materials is mostly cotton. Until today's modern rice paper is different from the traditional, especially for the treatment of ink painting, it is especially simple and simple. Without losing the atmosphere. This paper makes the following research on the inheritance and development of the embroidery art in the context of cultural and creative industries.

\section{The unique charm of Qiang embroidery art}

The traditional embroidery is mostly made by silk, and the artistic value of silk embroidery is extremely high. However, because the material is not easy to obtain, the price is very expensive, and the material of the silk product is easily damaged, and it needs to be kept away from the sharp weapon and carefully preserved. Once the embroidery is dirty, it is inconvenient to clean. If the embroidery is damaged, it will cause irreparable damage. Embroidery chooses Xiab as the base fabric, this ancient textile fabric. Has a unique fiber structure. First of all, it is environmentally friendly, and the production and use of the fabric is not polluted. Secondly, it is easy to preserve. Without the influence of the external environment, Xiabu can remain rotted for 1600 years. This unique material makes the embroidery more durable and has a higher collection value than other embroidery. For modern embroidery, the whole use of rice paper as the base fabric carrier, because the rice paper itself is not brittle for a long time, and will not fade, has the reputation of "paper life millennium", the embroidery is more resistant to corrosion and not afraid of insects, easy to save. . Even after years of baptism, Qiang embroidery can retain the appearance of the year and rejuvenate the artistic vitality of history.

The embroidery is selected as the base fabric, and the overall embroidery looks more quaint and rough, giving the viewer a sense of grandeur. The characteristics of the combination of coarse and 
fine, simple and delicate, delicate and atmospheric, fresh and simple in the embroidery, give a variety of visual impacts in a variety of ways. However, as people's art has risen, the demand for art has gradually increased. Xiabu cannot carry out mass production and processing of modern machines because of its fiber specificity, and the base fabric is easy to wrinkle due to uneven force during the embroidery process. The manual embroidery process is inferior to the speed of machine production, and the embroidery will also be produced. Mistakes can't satisfy the rising demand for crafts. Therefore, a brand new primer came into being. It is Xuan paper, this brand new embroidery with rice paper as the base fabric has got rid of the troubles of the past. Xuan paper is also a raw material of plant fiber, and can be mass-produced. It is not easy to wrinkle during the production process, and the use of rice paper in Chinese painting has a long history. Jiangxi unique The ink painting style of embroidery and rice paper can be said to be the best partner. This modern embroidery with rice paper as the carrier organically combines the art of Chinese painting with the art of embroidery, changing the fixed thinking of the original embroidery, facilitating the production of embroidery and the inheritance of the embroidery process.

The traditional embroidery theme is mostly flower and bird paintings, the color is more beautiful, and the embroidery is more in line with the characteristics of Chinese traditional painting. The overall use of ink painting as the design blueprint, more quaint sense. This is due to the unique origin of Jiangxi's first district and ink painting. Jiangxi is the former residence of the Badashan people in ink painting. The whole area likes this ink-inspired painting. The poem is in the painting and is spent in the poem. The embroidery style of Jiangxi people will naturally be biased towards the ink-inspired style, and the picture will be more concise and highly folk. This ink painting style of embroidery on the reverse side looks like a sketch, like drawing a draft as a draft. The most important feature of the whole is that the embroidery thread is perfectly integrated into the ink painting. The embroidery of various things in the real world is embroidered in the embroidery, close to nature, and restore the essence of everything in the world. If you look far away, it is more like an ink painting. You can't see the essence of embroidery at all. Even if you look at it, it is difficult to tell where the embroidery thread is. It is like a print of ink painting. You can only find it by touching it. The essence of embroidery. This kind of freehand embroidery works with realistic and realistic features, and the picture is full of layering and three-dimensionality. This "painting" with needles is an artistic innovation. It combines embroidery and painting with perfection. It also makes crafts full of artistic value and humanistic features. It can be said that it is a unique "business card" in Jiangxi.

\section{The inheritance and development of Qiang embroidery art}

\subsection{Inheritance characteristics of Qiang embroidery}

As a unique embroidery product in Jiangxi, Qiang embroidery has unique artistic value and collection value. The collection value of Qiang embroidery lies in its uniqueness and longevity. First of all, Embroidery is the only embroidery art that uses rice paper as the carrier of the fabric, and is the only one that combines ink painting and embroidery. The ink of ink painting will dry up due to the change of time. However, rice paper can be preserved for a long time, and it will last for a long time. Moreover, the embroidery thread dyeing process of the embroidery thread is good, the color is full and it is not easy to fade, which is more regrettable than the color change of ink painting over time. The combination of embroidery and ink is more like a great work. Because of this, Qiang embroidery has a very high technical requirement for the inheritor. It is a unique type of embroidery. To learn to embroider, it must have enough ink painting skills. Therefore, the inheritor of Qiang embroidery must be a person with ink painting skills. He needs Understand the layout of ink painting and clarify the basic concept of ink painting. Such high requirements lead to a long period of time for cultivating an excellent embroidery artist, and qualified 赣 embroiders need to train for three to five years, and it takes longer for the skilled artist to cultivate the embroidery technique. 


\subsection{Changes in the inheritance method of embroidery}

Because Qiang embroidery has high requirements for the inheritors, and learning to embroider can not bring considerable economic income, many people are reluctant to inherit this traditional craft, and Qiang embroidery is facing the dilemma of gradual loss. The unique historical culture of Jiangxi is facing a severe test, and the inheritance of embroidery is urgently needed to be resolved. Therefore, in order to continue the development of Qiang embroidery in Jiangxi, many changes have been made in the inheritance of this traditional art. It was mainly a major innovation in the way of inheritance. The founder of Qiang embroidery was the dry sister of Emperor Qianlong. The embroidered embroidered emperor was known as Yu Zhang embroidery and was deeply loved by Emperor Qianlong. Therefore, he was imprisoned by traditional ideas in his way of inheritance. Gu Ende, who brought Qiang embroidery into Nanchang, is the eighth generation descendant of $\mathrm{Gu}$ Shi's embroidery. For hundreds of years, Gu Jia has only passed on children, not to pass on women, and not to pass on outsiders. This kind of inheritance limits the inheritance range of Qiang embroidery. Many people who love embroidery are unable to touch the technique of embroidery, and if there is no child under the knee, or if the daughter-in-law does not like embroidery, the embroidery will Face the danger of extinction. Therefore, $\mathrm{Gu}$ Yuchun, the ninth-generation descendant, broke the imprisonment of traditional thoughts, introduced the embroidery to the masses of the masses, and opened the embroidered workshop to recruit the majority of embroidery lovers. After expanding the scope of enrollment, the embroidery gradually changed from art collections to handicrafts. Decorations. Such changes have made a significant contribution to the inheritance of Qiang embroidery.

\subsection{Development path of embroidery}

Under the background of the country's extensive support for cultural and creative industries, the in-depth development of Qiang embroidery is crucial for the Jiangxi region. Qiang embroidery has rich regional characteristics, including the endless wisdom of the ancients in Jiangxi and the constant innovation of art. This cultural heritage is profound, and the enduring art form should be combined with the contemporary business society. This combination can not only guarantee the unique inheritance of culture in Jiangxi, but also meet the continuous development of the local economy and create endless wealth for the people. The specific housing exhibition path can be diversified. We will try our best to promote the embroidery and become the brand of Jiangxi. Let people go to Jiangxi and think of Qiang embroidery. They are eager to see the "Shenshan true face" of Qiang embroidery. Jiangxi can promote the Qiang embroidery cultural tourism project, make rich and attractive advertising planning, let the public know about the embroidery culture, and know more people. People who like to embroider will definitely increase, want to know 赣 The embroidered people will organize a group tour to Jiangxi, and the tourism scenic spots developed by it can also drive the cultural industry around the scenic spot, sell regional specialty goods, and stimulate the regional economic domestic demand, so that the cultural products of Qiang embroidery bring more to the Jiangxi region. Economic benefits. On the other hand, in order to cater to the public's favorite, embroidery also needs to make modern changes, just like the original use of rice paper instead of Xiabu, embroidery can replace more modern materials suitable for embroidery. At the same time, the content of ink paintings of Qiang embroidery can be gradually changed. It is no longer limited to landscapes, flowers, birds and characters. It can embroider some things that are suitable for young people's aesthetics, such as fashion patterns, star shapes, and even private order according to individual needs. As long as the customer gives the pattern, it can be embroidered according to the pattern.

\section{Conclusion}

Under the background of cultural and creative industries, Jiangxi should make extensive use of the inheritance of Qiang embroidery to develop tourism with regional characteristics, so that regional culture can be widely spread, which is a blessing for cultural heritage. At the same time, it 
can attract foreign tourists to promote local economic development. It can not only promote cultural communication, but also solve the economic needs of the people in the region.

\section{Acknowledgements}

Fund Project: 2016 Jiangxi University Humanities and Social Sciences Research Project

\section{References}

[1] Long Qinghua. The inheritance and innovation of Fanjing Mountain's mask art under the background of cultural and creative industries [J]. Popular Literature, 2018 (10): 44-46.

[2] Cheng Lingyun, Han Jiangfang. Inheritance and Development of the Mask Art in the Background of Cultural and Creative Industries [J]. Popular Literature, 2015(10): 36-37.

[3] Liu Na. I see the unique artistic charm of Qiang embroidery [J]. Popular Literature, 2013 (23): 4 